\section{Zahlen des Monats}

\section{Wer wählt was?}

Die Bundestagswahl im Herbst wirft erste Schatten voraus. Die Zeit der Umfragen und Wahlomaten hat begonnen. Für wen die Ärzte am 24. September ihre Kreuze machen wollen, das hat das Internetportal Ärztenachrichtendienst herausgefunden. Laut einer Umfrage unter 1.700 Haus- und Fachärzten wünscht sich die Ärzteschaft nach der Bundestagswahl erwartungsgemäß eine Regierungskoalition aus CDU/ CSU und FDP. 31 Prozent würden die Liberalen wählen und 30 Prozent die Union. Doch nicht alle setzen auf Schwarz-Gelb. Zehn Prozent der teilnehmenden Mediziner würden ihre Stimme der SPD geben, 15 Prozent der AfD, sieben Prozent den Bündnisgrünen und vier Prozent den Linken.

\section{Wer arbeitet wo?}

Der Trend geht seit Jahren in eine Richtung: In Deutschland arbeiten immer mehr Menschen im Gesundheitswesen. Nach Angaben des Statistischen Bundesamtes waren in der Branche Ende 2015 rund 5,3 Millionen Beschäftigte tätig. Das waren 112.000 Personen oder 2,2 Prozent mehr als im Vorjahr. Die Hälfte der Beschäftigten arbeitete in Teilzeit oder noch weniger. Das Statistische Bundesamt führt den Anstieg unter anderem auf die demografische Entwicklung und damit auf die stetig steigende Zahl von Arbeitskräften in der Altenpflege zurück.

\section{Wer scheitert womit?}

So schön der positive Beschäftigungstrend im Gesundheitswesen auch ist, der niedergelassene Arzt oder Zahnarzt hat seine ganz ureigenen Probleme. So hat die Zahl der insolventen Arzt- und Zahnarztpraxen im vergangenen Jahr zugenommen. Wie das Statistische Bundesamt mitteilte, mussten von Januar bis November 2016 bundesweit 94 Arzt- und Zahnarztpraxen Insolvenz anmelden. Im Jahr zuvor waren es zehn Praxen weniger. Unter den Betroffenen waren 50 Zahnarztpraxen, 30 Facharztpraxen und 14 Praxen von Allgemeinmedizinern. Die voraussichtlichen Forderungen beliefen sich auf 89,3 Millionen Euro, darauf entfielen auf die Zahnärzte 26,2 Millionen Euro.

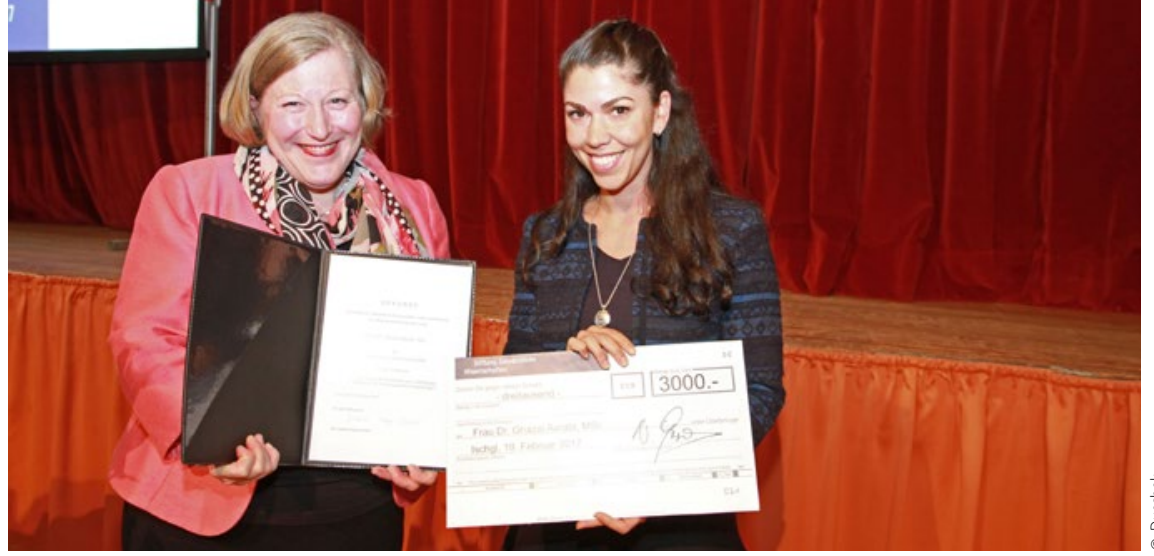

Zahnärzte tagen im Tiroler Skiort Ischgl

\title{
FVDZ-Winterkongress eröffnet
}

Bereits zum zweiten Mal hat der Freie Verband Deutscher Zahnärzte (FVDZ) Zahnmediziner und Praxismitarbeiter in den Tiroler Skiort Ischgl zum insgesamt 49. Winterkongress eingeladen. Bei der Eröffnung am vergangenen Sonntag erinnerte sich der stellvertretende FVDZBundesvorsitzende, Dr. Peter Bührens, dass er selbst als Student einst Teilnehmer des Winterkongresses war und so zum FVDZ fand. Umso erfreulicher sei es, dass die Tradition fortlebe und auch in diesem Jahr eine ansehnliche Zahl an Zahnmedizinstudenten angereist sei.

Unmittelbar an die gewohnt kurze und humorvolle Begrüßung erfolgte die Übergabe des mit 3.000 Euro dotierten Förderpreises der Stiftung Zahnärztliche Wissenschaften. Die stellvertretende FVDZ-Bundesvorsitzende, Dr. Gudrun Kaps-Richter, überreichte den Preis an Dr. Ghazal Aarabi, Zahnärztin und wissenschaftliche Mitarbeiterin in der Poli- klinik für Zahnärztliche Prothetik am Universitätsklinikum Hamburg-Eppendorf, für ihr Forschungsprojekt zum Thema „Entzündungen der Mundhöhle als unabhängige Risikofaktoren für kardiovaskuläre Erkrankungen“.

Als Höhepunkt der Eröffnung referierte Dr. Markus Merk zum Thema „Sich(er) entscheiden“. Merk, Zahnarzt aus Kaiserslautern, ist als dreimaliger Träger der Auszeichnung „Weltschiedsrichter“ Fußballfreunden rund um den Erdball ein Begriff. Neben Weltmeisterschaften pfiff er das legendäre Endspiel der Europameisterschaft zwischen Griechenland und Portugal im Jahr 2004 und hält mit 339 Partien den Schiedsrichterrekord in der Fußball-Bundesliga. Mit mitreißenden Worten vermittelte Merk, wie richtige und manchmal auch unrichtige Entscheidungen schnell, konsequent und nachhaltig getroffen werden.

TRUMP VERUECT SENE ENGSTEN VERTEATIEN 